Apesar da perseverança com a qual Sigmund Freud se dedica a provar a existência da sexualidade infantil, mesmo no interior da comunidade psicanalítica, a infância não foi pacificamente conceitualizada. A relutância de toda uma sociedade em aceitar a revelação da precocidade do ser humano traduziu-se, entre os psicanalistas, em embates cuja representação mais concreta foi a das controvérsias ocorridas em 1926-27 entre Anna Freud e Melanie Klein. Foi esta última que defendeu a precocidade extrema do Complexo de Édipo, abrindo assim espaço para uma visão estrutural da infância. Psicanálise; Infância; Melanie Klein

THE INVENTION OF THE PSYCHOANALYSIS CHILD OF: FROM SIGMUND FREUD TO MELANIE KLEIN

Despite the patience devoted by Sigmund Freud to prove the existence of childhood sexuality, even in the heart of the psychoanalytic groups, the concept of childbood bas been not unmistakably established.

The relutance of a bole society to accept the unveiling of such a precocity in the buman being brought up, among psychoanalists, conflicts which the most representative case bas been the controversies betwen Anna Freud and Melanie Klein. It was the latter, defendig the extreme precocity of the Oedipus Complex, who gave room, to a structural view of childhood.

Psychoanalisis; Childbood; Melanie Klein

\section{A INVENÇÃO DA CRIANÇA DA PSICANÁLISE: DE SIGMUND FREUD A MELANIE KLEIN}

Diana Myriam Lichtenstein Corso

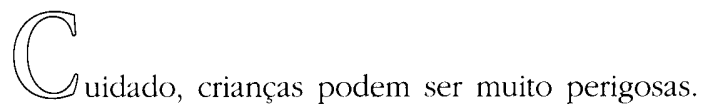
Só vendo para creer que seres de menos de um metro, sem nenhum tipo de poder paranormal, possam ser consideradas capazes de encarnar o demônio e a mais perversa das perdições. No entanto a fantasia e sua gêmea vistosa, a ficção, não cessam de assim qualificá-la. O cinema é o palco preferido de repetidas versões de crianças assassinas, sádicas ou perversas, estejam elas possuidas ou não, vide O exorcista, Poltergeist, Anjos malvados e outros. É a aparente paradoxa entre a inocência infantil e a perversão adulta que produz o aspecto particularmente chamativo da maldade infantil. Porém não só o mal mas também o sexo na infância foi fonte de muita controvérsia. Embora o mal e o sexo sejam o que o humano tem de mais enigmático resistimos o quanto podemos a ver as crianças envolvidas nisso.

Não é à toa que a afirmação mais provocante de Sigmund Freud não foi, ao ver do próprio, que se possa adoecer de desejos inconfessáveis, constatação a que foi

Psicanalista, Membro da Associação Psicanalítica de Porto Alegre 
levado pela clínica e pela análise de seus sonhos, mas sim a descoberta da sexualidade infantil. Uma descoberta muito diferente de um continente nunca antes aportado. Seria algo como descobrir o Big Ben em Londres e afirmar a sua existência a milhares de incrédulos ingleses. Digo isto porque todo ser humano já foi criança um dia, queira lembrar ou não.

A infância faz sua entrada na elaboração psicanalítica através do relato das histórias de sedução das histéricas: a maior parte destas afirmava ter sido desejada sexualmente pelo pai, ou susbstituto, que teria manuseado seu corpo de alguma forma que sugerisse essa atração anormal.

Foi assim que a teoria psicanalítica em seus primórdios foi jogada na máquina do tempo. Ali onde pensava se estar as voltas com magnitudes de energia represadas, liberadas via sintoma, etc., irrompe o relato, a história, a versão. Explicando melhor: num primeiro momento, a compreensão do doutor Freud para os fisiológicamente inexplicáveis fenômenos da histeria não foi muito diferente da dos antigos que os atribuiam à fúria uterina da fêmea insatisfeita. Os primeiros casos de Freud, encontravam na abstinência sexual uma lógica explicação para a possessão de uma parte do corpo por algo que não encontrava outra expressão.

Partindo da admissão de uma fonte erótica para a histeria, o que é já em si interessante, pois reconectava as descobertas de Charcot com séculos de história da medicina, Freud foi mais longe, ao admitir, logo a seguir, que se tratava de um discurso inscrito no corpo.Tratava-se de um desejo recalcado cuja insatisfação encontrava saída no sintoma histérico. Porém, mais um passo ainda esperava, o de inserir este desejo recalcado na história da paciente. Os relatos que o psicanalista escuta confirmam o que a viagem interior de Freud indicava, a histérica sofre de reminiscências, é do passado que provém as histórias que dão lógica ao evento. Porém há o detalhe que faltava: estas reminiscências não são de algo que ela viveu, mas de algo que ela desejou ter vivido.

O caso prínceps para compreender este mecanismo não está nos Estudos sobre a bisteria, encontra-se relatado no Projeto para uma psicologia científica de 1895 . Trata-se da mesma jovem que anos depois tem um sonho seu celebrizado com o apelido de "Sonho de Irma", ela queixa-se de que não pode entrar em lojas sozinha. Esta dificuldade aparentemente resulta de que aos oito anos teria sido assediada por um homem em uma confeitaria. O problema é que, pouco tempo depois, ela retorna a esta loja, como em busca de novas carícias e é nesta volta que reside a lembrança patógena, no fato da menina, ao ir de encontro a essa situação que se supunha que ela só tinha motivos para evitar, ter engajado um desejo na sedução (Freud, 1990)

Portanto, a descoberta da importância da infância decorre da existência não só de uma sexualidade infantil, mas de um sujeito sexualmente desejante na infância. Assim, a psicanálise passa a se 
conectar com a história do sujeito, de um ser que desde muito cedo escreve suas páginas com seus desejos, proibidos e realizados, admitidos $\mathrm{e}$ recalcados. A infância recebe em seus braços tudo aquilo de que se lhe considerava ainda imune, acrescido do problema de que estas vivências são compreendidas como formadoras, constituintes. Isto obviamente faz da infância objeto de atenções teóricas e preocupações pedagógicas.

Em 1905, num texto denominado Três Ensaios para uma Teoria Sexual, Freud descreve as modalidades do desenvolvimento da sexualidade infantil. A criança sai deste texto transformada em "perverso-polimorfa", tendo sido desvendado o mapa do percurso pulsional. Cria-se aqui um corpo ao qual embora não the seja negada uma certa pertença à natureza, o faz de forma intrínsecamente pervertida, ou seja, busca algo que nada tem a ver com necessidades ou funções vitais. Um corpo suscetível de descaminhos, enfim, um corpo pulsional.

Ao retroagir à infância a origem da sintomatologia, Freud faz da história individual de cada sujeito a responsável pelo seu vir a ser. É importante ter bem claro que até o aparecimento da teoria freudiana, buscava-se na história genética do sujeito a origem de determinada doença psíquica. Buscava-se na história, mas no sentido de sua história biológica, genética, a explicação para os males.

Sabe-se já ao ler o Freud do início do século, que o mapa de uma subjetividade é traçado na infância e, diferente dos desígnios unívocos de um mapa astral, o nosso é construído aos poucos, passa por periódicas mudanças de traçado, e se confunde com a gênese da nossa imagem corporal.

Qual a novidade? Pode-se argumentar que os educadores já há duzentos anos sabiam que era preciso formar um sujeito introduzindo-o nos preceitos morais desejáveis. Notórios moralistas do calibre de Rousseau, dedicaram muitas páginas ao cuidado necessário para formar homens de boa cepa! Desde a revolução francesa, acredita-se que berço não é destino, e investe-se na educação como fonte de riqueza e liberdade de escolha.

Certamente Freud não descobriu a infância, ele apenas a "complicou", desvendando o caráter interno deste processo, fazendo da moral a herdeira do amor dos pais (constituição do superego), colocando os desejos parentais no lugar de molde do ideal, a fôrma com a qual o sujeito se mede, e fazendo de tudo isto um imprevisível processo inconsciente sujeito a suscitar a neurose e outros sofrimentos.

Freud arrancou a ilusão de objetividade da ainda jovem crença na possibilidade de fazer um homem novo, filho da liberdade com o saber. Não se deduza disto que não vejo em Freud o sonho iluminista: ele acreditava que da liberdade de discurso da criança, da diminuição do jugo que mantinha a sexualidade sob um véu de hipocrisia, adviria um homem melhor. Freud acreditava no poder liberador das palavras que curam. O problema é que justamente por sua visão complexa da subjetividade, da imprevisibilidade dos efeitos das vivências, Freud baniu qualquer sonho de objetividade possível na construção educativa de um novo homem. A partir daí, não temos mais nenhuma receita para gerar o homem liberto $e$ inteligente do sonho iluminista.

Se tivessemos que nos contentar somente com a existência da criança perversa polimorfa dos Três Ensaios, vá lá. Mas não contente com as tramóias complexas e imprevisíveis do desenvolvimento de um indivíduo, Freud golpeia o próprio eixo de nosso funcionamento. Agarrados à lógica compreensí- 
vel do princípio do prazer, ainda nos mantinhamos mais próximos de algo mais natural: o que nos guia seria uma forma complexa de bem estar. Porém, mais uma vez, ao elaborar a questão da repetição, finalmente consolidada no conceito de pulsão de morte, Freud pôs limites ainda maiores na objetividade que a própria psicanálise almejava. Se ainda podíamos depositar otimistas esperanças no caráter libertador da erradicação das hipocrisias religiosas e pedagógicas, agora nada mais garante o $\mathrm{ca}^{-}$ minho para a felicidade, não existe rumo certo...

Mas, por falar em morte, porque alguém se apegaria àquilo que lhe ameaça a existência? Porque não podemos dispor da bovina felicidade de rumar ao matadouro inconscientes de nosso destino? Nossa natureza imprevisível e mórbida, leva-nos a existir bordeando a possibilidade de não ter sido ou de deixar de ser a qualquer momento. Remoemos sem cessar nossas tristezas e cultivamos as feridas da alma com apaixonado zelo. Por isso não entregamos ao psicanalista de bom grado nossas mazelas para que ele nos livre delas. Ao elaborar a repetição em 1919, em "Para Além do Princípio do Prazer", Freud teorizou que só nos livramos de nossos mais ocultos e arraigados sofimentos à condição de vivê-los uma última vez, na transferência, como um casal que se separa troca um último beijo de adeus.

Assim, deixando-nos privados da objetividade na educação e na terapêutica analítica, Freud deixou nossos sonhos de construção de um sujeito menos sofredor bastante abalados. Mas não faltaram os que sonharam a restituição da utopia, a psicanálise com crianças e a educação psicanalíticamente orientada foi o berço dos esperançosos.

Karl Abraham, o discípulo dileto de Freud, foi um grande representante desta tendeência. Prova disto é que considerava que "a vida instintiva da criança persiste em alguns adultos (precisamente os neuróticos) de maneira positiva e inconfundivel" (Abraham, 1973, P. 15). Partindo-se desta linhagem cronológica direta dos sintomas, que permaneceriam como restos de infância sobreviventes nos adultos, a análise poderia readministrar os problemas gerados por faltas ou excessos de coerção na educação de um determinado sujeito.

É preciso compreender que, para Abraham, o mapa subjetivo, ou seja o traçado de nossa história por sobre nossos corações e mentes, é determinado conforme as fases libidinais e diretamente relacionado com a experiência de termos sido educados. Assim, é fácil encontrar o ponto nodal do problema e corrigir a falha no desenvolvimento, da qual o sintoma de hoje seria como uma luz no painel indicando uma avaria no motor.Desta forma a relação com o passado é menos dinâmica, assim, ignorando as liçōes da pulsão de morte o discípulo preserva a utopia do mestre.

Anna Freud sonhou mais que ninguém com algum tipo de objetividade no vir a ser de um sujeito, apostou em mecanismos e na possibilidade da observação detalhada como forma de investigação do desenvolvimento humano. Se podemos dizer que seu trabalho foi de grande valia para a psicologia, pouco pôde ela com ele na evolução da teria psicanalítica. Como pedagoga que era, apostou na reestruturação de um sujeito ainda criança através de uma liberação de impulsos recalcados e a colocaçâo destes sob a égide educativa do ideal da analista.

E é aqui que também se inicia a obra de Melanie Klein: o berço de sua teoria é precisamente o sonho pedagógico da educação psicanalíticamente orientada de seu filho Erich. Conhecido em seu texto The development of a 
child, apresentado em 1919, mas publicado em 1921, como Fritz (Klein, 1975).

É através do relato dos diálogos que constituiram essa educação, da atenção que dispensava às elucubrações de seu caçula, discutindo com ele sobre a origem dos bebês, a existência de Deus e todas as ramificações de sua curiosidade, que Melanie apresenta sua candidatura e torna-se membro da Sociedade Psicanalítica Húngara. Esta história é a da tentativa de assumir a maternidade e da elaboração do seu ideal relativo a este filho que, embora fosse o terceiro, era o primeiro que concernia mais diretamente a ela, pois os outros foram criados com a forte presença de Libussa, sua mãe.

The development of a child, encontra uma mulher já amadurecida por um profundo sofrimento neurótico, às vésperas do divórcio, mas já proveniente de uma análise com Ferenczi. Este texto inaugural para Klein tem, exatamente como acontece no caso do pequeno Hans, um seguimento onde a relação com a criança é retomada, são dois momentos de uma análise.

Em ambos casos, Fritz e Hans, o primeiro momento pedagógico tinha o mote de uma apresentação do discurso da criança como confirmação das teorias freudianas sobre a sexualidade infantil, porém, num segundo momento, já presente o objetivo terapêutico, a criança não era objeto de curiosidade mas sim de preocupação. Hans sintomatizou numa fobia e Fritz começou a apresentar inibições variadas, revelando-se uma criança de desenvolvimento lento e limitado. Isto teria sido talvez motivo para desistir e considerar um equívoco as iniciativas de educação psicanalíticamente orientada que foram empreendidas. Porém, estes pais psicanalistas, como estudiosos e pacientes da psicanálise, possuiam uma ética pessoal que passava pela admissão da própria neurose e não se atemorizaram mediante o surgimento de sintomas em seus filhos.

Assim como o pai do pequeno cuja análise foi relatada em 1909 por Freud em Análise de uma fobia em um menino de cinco anos, Melanie venceu as incertezas que abatem qualquer pai ou mãe, mesclando uma tolerância inédita aos sintomas de Fritz, com uma crença no poder liberador da enunciação das fantasias. Foi nesse processo que Hans conseguiu construir um lugar para seu pai e Erich para sua mãe e foi assim que o pai de Hans e Melanie conseguiram ser pai e mãe.

Visto desde este ângulo, parece que temos aqui algo mais do que um sonho pedagógico formal: encontra-se representada neste casal a gênese do que viria a ser a relação dos adultos e crianças no século XX. Vemos aqui a paternidade e a maternidade oriundas de um sofrido processo cheio de incertezas sobre o resultado e sobre as bases en que se assentam o saber e a herança. A condição de ser pais extrai aqui sua vacilante condição de possibilidade de um saber, no caso a psicanálise.

Pais e mães desempenham seu ofício sem nenhum tipo de automatismo hereditário. A paternidade se instaura encarando os seus antepassados como uma terra de fertilidade duvidosa, regada de neurose, sobre a qual plantar suas próprias convicções. Assim as teorias infantis, teorias confeccionadas pela criança e utilizadas para compreender o mundo, quer sejam as sexuais, como descoberto por Freud, quer sejam as hipóteses cognitivas (herdeiras das primeiras), como teorizado por Piaget, são $o$ instrumento por excelência do vir a ser da criança.

Observem esta virada fundamental que é onde vai residir a marca de diferença da psicanálise para a tradição moralista: busca-se na criança um saber. Mais do que exercer a autoridade for- 
madora das convicções dos adultos sobre a criança, a paternidade passa a ser vivida como condição de ignorância, os pais psicanalistas ao invés de incutir procuravam saber junto da criança qual sua versão do pai. Melanie encarna esta virada como ninguém, sua crença na precocidade das fantasias e da constituição do sujeito faz com que tenhamos desde o começo uma subjetividade com que dialogar, mais do que uma criança a formar.

A obra de Melanie chega justamente em um momento histórico no qual o sexo e a morte começavam a ser encobertos no discurso psicanalítico, a marca da repetição sobre o imensurável desejo e a pulsão de morte perdiam espaço conceitual na medida em que teóricos supostamente ponderados os atribuiam a excessos senis do mestre.

A obra de Melanie mais uma vez desmonta o caráter mecânico que a criança começava a assumir, fruto da paixão pedagógica reinante. Seus textos são tão estranhos quanto o discurso da criança para os poucos que tem coragem de ouvi-la. Na verdade, na clínica com crianças temia-se inúmeras coisas que faziam resistência à prática convencional, desde a inadequação do sujeito infantil à técnica, até o desencadeamento de impulsos selvagens pela revelação de conteúdos inconscientes em sujeitos ainda não completamente civilizados. Convém, no entanto, manter acesa a questão do que é que realmente constituiu a dificuldade no advento desta prática, mantenhamos esta questão até o fim do corrente trabalho...

A clínica psicanalítica com crianças deve suas origens ao pai de Hans e a Hermine von Hug-Hellmuth, que conduziu uma intervenção analítica com seu perturbado sobrinho, inaugurando esta prática. Porém a análise de crianças tornou-se corrente, diferente do caráter de excessão que tivera até ali, a partir de Melanie Klein e Anna Freud.

Para Anna Freud, a clínica poderia ser "adaptada" aos reveses da infância, mas a condição infantil é por ela considerada uma obstrução mais do que uma especificidade. Nesta ótica, o paciente ideal é o adulto e ela relata, por exemplo, como fez "analisáveis, no sentido adulto, seus pequenos pacientes" instaurando a praxe de um preparo, um "treinamento", com a criança, que "durará tanto mais, quanto mais discrepante esteja o estado original da criança que acabamos de descrever em relação ao paciente adulto ideal" (Anna Freud, 1946, P.16 - 17)

Aos três requisitos que Anna Freud considerava necessários para o desenvolvimento de uma análise: (a) a consciência da doença, (b) a confiança na análise e no analista e (c) a decisão interior de se analisar; a todos eles a criança respondia negativamente.

Para a senhorita Freud, a consciência da doença era inexistente nas crianças, a queixa vinha dos pais. A transferência, que permitiria a confiança na análise e no analista também impossível, pois não julgava possível a neurose de transferência na infância visto que "a velha edição ainda não se esgotou". Por último, a decisâo interior de se analisar, pressupunha a existência de um sujeito de alguma forma constituido, com o suficiente vivido de forma a produzir uma massa de subjetividade, de inconsciente, de fantasias, enfim, um lastro sobre o qual possa um sujeito fundar a queixa e a transferência. Para supor isso numa criança, é preciso crer numa constituição precoce, numa presença das figuras parentais como constituintes da subjetividade, internalizadas diria Klein, desde muito cedo.

Com todos os entretantos listados por Anna Freud, era de se supor que só poderia tentar-se algo parecido com uma análise em crianças da latência em 
diante. A análise precoce, antes da óbvia e visível condição civilizada do ser humano alfabetizado da latência, era considerada um perigo, podendo inclusive liberar expressões da perigosa sexualidade perversa polimorfa.

Para Melanie o debate rumava por outros caminhos, pois, defensora que era de uma intervenção mais analítica que terapêutica, denunciava em Anna os descaminhos de quem muito se preocupa com a consciência, quer seja da doença ou de qualquer outra coisa.

Klein possuia uma verdadeira fé na importancia de buscar a expressão de conteúdos inconscientes e acreditava que a criança estava em melhor posição que os adultos para encontrá-los. "Podemos estabelecer um contato mais rápido e seguro com o inconsciente das crianças" (Klein, 1975, P. 141), escreve ela em 1927, por ocasião dos embates com Anna, e acrescenta "as crianças não são fundamentalmente distintas dos adultos. Só o que ocorre é que nas crianças o 'eu' não se desenvolveu ainda plenamente e portanto elas estão muito mais governadas pelo inconsciente".

Evidentemente que estas condições de acesso ao inconsciente infantil, eram para Klein não só uma carta branca para a análise de crianças mas também um argumento fundamental para criticar os desvios de sua rival, principalmente na acusação mais corrente na época de que Anna não tinha análise pessoal suficiente para ousar trafegar pelo inconsciente alheio. Argumentadora inteligente, Melanie espeta a adversária dizendo que "a questão nào é se a análise de crianças pode ir tào profunda como a dos adultos, mas se é o caso de faze-lo", indicando que Anna apresenta como impossível aquilo que não quer e não se atreve a fazer. Assim sugere a resistência da adversária, impedida de se colocar em um lugar de analista em função do caráter incestuoso da análise realizada junto ao papai Freud. Época de poucas papas na língua...

Ao problema da adequação da psicanálise à infância, devemos dar uma resposta estrutural, que diz respeito à relação da criança com seu inconsciente: para tanto, precisamos acreditar que há uma constituição psíquica muito precoce, o que nos permitiria pensar em recalque e sintoma na infância. Porém se os há implica que algo maior do que o simples medo da autoridade real dos pais está produzindo efeitos, ou seja, uma criança não faria um complexo sintoma fóbico, ou não constituiria rituais obsessivos, se para obter o amor dos pais ou testar o poderio paterno bastasse fazer uma demanda direta. A complexidade sintomática da infância informa de uma complexidade subjetiva, precisamos, portanto, pensar as figuras parentais como uma construção interna do sujeito desde muito cedo, desde sempre diria Melanie. Eis aqui a necessidade de ocuparmo-nos da concepção de constituição do sujeito em Klein.

Explicitando minimamente este processo: encontraremos uma boa fonte para a suposição de um simbolismo precoce, na aparentemente absurda hipótese kleiniana de um édipo completo em seres humanos que ainda contam sua idade em meses, cujo vir a serapoia-se, ancora-se ainda corpo materno. Na "geografia do corpo materno" como diria Klein.

Observamos no texto de Klein, sua concepção da gênese da imagem corporal a partir do corpo da mãe, pois ela a concebe como um resultante do movimento da libido, regido pelo princípio do prazer, que leva à identificação das partes do próprio corpo com as do corpo da mãe que proporcionam satisfação, assim a boca passa a existir simbólicamente no seio. Através desta que foi denominada de "identificação primá- 
ria" (Petot, 1987, P. 65) o sujeito passa a sexualizar as primeiras representações de sí e, assim sendo, o recalque advém para transformá-las em símbolo.

A "geografia do corpo materno" é uma expressão oriunda de problemas de orientação espacial de seu filho-paciente Fritz, que encontraram soluçào através da interpretação de fantasias de "penetrar no corpo da mãe e investigar seu conteúdo, com as passagens para entrar e sair dele e os processos de fecundação e nascimento".

Mas é numa nota de pé de página de seu Análise Infantil, texto de 1923, que introduz esta bela expressão justamente numa interessante discussão com seu analista Karl Abraham, sobre isto nos diz Melanie: "Abraham assinalou que $o$ interesse em relação a corpo da mãe é precedido, num estágio muito precoce, pelo interesse em relação ao corpo do próprio sujeito"(Klein, 1975, P. 99).

Assim Abraham afirma a existência de algo no sujeito anterior à existência do/no Outro, algo como o primeiro período narcísico suposto por Freud. Melanie não o contesta, mas afirma que se algo é passível de elaboração posterior, ou seja, merecedor de repressão, e portanto de simbolização, só o é aquilo que diz respeito ao desejo incestuoso. Sabemos que é a repressão que dá estatuto de existência psíquica às produções do sujeito, ou seja, suas fantasias. Portanto, se há algo anterior à repressão, não seria digno de representação psíquica, sua existência, então, não passa de uma suposição teórica, visto que o sujeito dela não tem registro.

A geografia do corpo materno provém da forma como seu filho paciente denominava de "limites" as extremidades de seu corpo, e de "uma montanha que ele escalava" sua mãe assim como em seu ventre podia encontrar um grande rio. Eis o amor de um filho fazendo poesia da màe e esta, por sua vez, tomando suas palavras como sábios dizeres reveladores de que a representação do corpo próprio é uma forma de especularizaçào, de ver-se nela.

Ao acreditar que é só nas fantasias incestuosas que se pode encontrar as origens do sujeito, ao remeter estas mesmas a momentos tão remotos da vida humana, Melanie torna ternário o complexo que origina o ser humano. $\mathrm{O}$ sujeito origina-se não só na mãe, mas numa complexa funçào que articula o corpo materno e sua interdição. É neste último termo, no sofisticado mecanismo que barra a reabsorsào pelo corpo da mãe, que Melanie supõe encontrar esta função terceira que chamaríamos de pai. "Pai" para ela, tomado ao pé da letra, é um pênis contido no interior do corpo da mãe, são os bebês que o genitor coloca no ventre desta, são "as figuras parentais combinadas" ou "imagem unificada dos pais" (Petot, 1987, P. 151), espécie de monstro formado pelo coito dos pais que assombra as fantasias infantis. Mas acredito que não é só isso. Em nome do "Pai" ela constitui este sistema que torna inviável a fusão com a màe. Trata-se de algo que embora ela ponha a funcionar, ela pouco nomeia. Portanto, na precoce interdição do incesto, ou seja, naquilo que ameaça a integridade da criança se ela possuir e se deixar possuir pela mãe, encontramos toda a novela edípica.

A questão é porque é necessário percorrer caminhos tão tortuosos para admitir a condição ternária do berço do sujeito. Uma resposta talvez esteja na dificuldade da própria Melanie de reconhecer a paternidade de seu marido e do próprio Freud, mas isso são conjecturas, outra explicação talvez esteja no fato de que para o sujeito infantil em seus primórdios o "Pai" é 
exatamente uma modalização do discurso materno. É na mulher que um homem deve produzir efeitos para que advenha a posição paterna! Isto não encontra expressão de clareza até Lacan, mas de alguma forma, podemos encontrar já no discurso kleiniano o esboço involuntário daquilo que depois seria teorizado como função paterna.

No interior da obra kleiniana, a hipótese da precocidade da constituição subjetiva advém da constatação da angústia em crianças muito pequenas, observação clínica extremamente acurada, pois qualquer um que esteja fadado ao convívio com crianças será rapidamente levado a constatar que suas vidinhas são extremamente complicadas. Não há outras formas de explicar as cólicas que dilaceram o bebê, a força dos pavores noturnos, os complicados rituais cotidianos, tão meticulosos quanto absurdos, se não pensarmos em alguma sofisticação da nascente subjetividade. Foi dessa evidência clínica que adveio a hipótese da angústia a qual, para Klein, de acordo com a segunda teoria da angústia em Freud, não se trata apenas de acúmulo de energia represada e é desde sempre, associado ao complexo de édipo

A transferência na infância tornase possivel para Melanie porque para ela os pais são figuras introjetadas desde sempre, não há qualquer outra relação possível com a criança que não seja transferencial, a própria relação com os pais reais é transferencial. Neste sentido, a análise de uma criança não difere muito de outros cenários de sua vida. Todo seu cotidiano visará modular sua relação com as fantasias que constituiriam sua verdadeira essência. Nada surpreendente então, que ela tenha recomendado a análise de todas as crianças como uma forma de otimizar o trabalho educativo. Bem como empreendido a análise de muitas crianças pró- ximas, inclusive seus três filhos.

Seu ponto de vista, que privilegia a posição da criança sobre o caráter traumático do vivido, evidenciando a fantasia e relativizando os fatos, eliminava a forma "direta e inconfundível" preconizada por Abraham. É o fim da simplificação do vivido equivalendo ao marcado, pós Melanie a vida é algo a ser mastigado e digerido pela criança. Embora tenha tido este mérito de ter revelado a presença muito precoce do crivo da subjetividade infantil, a teoria kleiniana tinha o demérito de reduzir drásticamente a importância dos pais reais e descartar completamente qualquer intervenção junto à família. Os pais podiam ser, no máximo, bons analistas.Ela se importava tão pouco com o incosciente parental, quanto pouco pôde admitir em seus filhos-pacientes as reverberações de sua própria neurose.

É claro que recalcar a importância da família, privilegiando o delicado equilíbrio do mundo interno, a deixa com problemas para a explicação da origem das particularidades do sujeito, acabando por se render à hipótese quantitativa que tanto incomodou seus predecessores. Anna Freud se encrencou com a complicada medida da educação, na busca da "X" quantidade de repressão que produziria uma "Y" quantidade de neurose. No outro extremo, para Klein faria parte da gênese do sofrimento neurótico uma quantidade de angústia persecutória ou depressiva" maior do que o normal. Deixando o sujeito livrado apenas a seus processos internos, termina por se buscar algum tipo de essência individual, ou melhor, de predestinação restrita a etéreas quantidades de energia, tão compreensíveis quanto as correntes de ar e seus resultados metereológicos. Tudo isso de uma maneira caricatural, deixando-se levar pelo raciocínio da teoria, pois a analista Melanie, em seus relatos, é mais 
atenta aos pais.

Mas por falar em recalque do pai, podemos dizer que embora Melanie tenha sido contemporânea de Freud, para ela ele já estava morto. Podemos com certeza dizer que para Klein, Freud embora vivo ainda, era já um texto. Podemos situar uma extrema preocupação em assegurar-se a filiação freudiana, intensamente presente, por exemplo, nas controvérsias com Anna Freud, em 1927, onde debatia-se qual das duas era verdadeiramente merecedora do espólio freudiano, qual forma de conceber a psicanálise de crianças continha a essência da teoria do fundador e qual a corrompia e a abandonava.

Melanie começa a clinicar mais de 10 anos antes da morte de Freud, mas a história não registra nenhum encontro pessoal de ambos, nenhum diálogo, apenas um pálido comentário, em cartas de Freud, sobre o debate em que sua filha se degladiava com Klein, prestando, óbviamente, um reservado apoio a sua filha. Porém esta seguidora de seu escritos, analisada por dois de seus discípulos mais diretos e diletos, Karl Abraham e Sandor Ferenczi, na condição de neta do fundador, soube lidar com o seu texto de forma a tomar "Para Além do Princípio do Prazer" como algo a mais do que a simples presença do câncer em Freud.

Pouco preocupada com a iminência da morte daquele que para ela nunca foi um personagem encarnado, Melanie pôde trabalhar com o sujeito nos limites da existência como até então ninguém o havia feito. O texto freudiano de 1919 nos confronta com a beira do precipício, ali ficamos sabendo que ser ou não ser é uma questão sempre recolocada pela vida, que estamos sempre remetidos a um lugar onde nosso ser, ou aquilo que compreendemos como tal, o querido ego de Anna Freud, encontra permanentemente seus limites.
$\mathrm{Na}$ repetição conceitualizada neste texto, encontramos a insensatez dos sintomas elevada a sua máxima potência.

Podemos nos atrever a afirmar que esta leitura tenha sido uma das origens da extrema tolerância clínica de Melanie, que pôde, por exemplo, emprender um trabalho com crianças extremamente desestruturadas, ou não estruturadas, melhor dizendo, sem medo do circuito que as tornava tão apegadas à sua própria anulação subjetiva. Ao tomar pequenos autistas e psicóticos aos seus cuidados e suportar suas inexistências existenciais ela conheceu o ser humano em suas bordas e pôde elaborar uma teoria do vir a ser psíquico que só encontrou sequência e consequência nas teorias de Lacan sobre a constituição do sujeito. Diga-se de passagem, que também Lacan graças à sua extensa trajetória psiquiátrica que o levou para junto da psicose em suas mais dramáticas formas, também conheceu com quantos paus se faz uma canoa, de que consistência depende um ser humano para tornar-se tal.

Para finalizar, uma última nota, das tantas que poderíamos tomar no rodapé dos textos kleinianos.

Atenção:, a teoria kleiniana deve ser lida desde o ponto de vista do sujeito em constituição, a ótica é a dos olhos da criança. As fantasias, processos e elaborações da sua teoria não contemplam o ballet, a coreografia da família, a saber, a função paterna e materna, o lugar da criança de objeto do desejo dos pais, os diferentes registros, feminino e masculino dos pais, não busque esses pontos de vista nos textos de Klein.

$\mathrm{O}$ que se pode procurar e achar no texto kleiniano é um trabalho de arrolamento de fantasias fundantes da subjetividade humana. Embora saibamos o quanto estas fantasias registradas tenham tido sua coloração fortemente marcada pelas tintas do imaginário da 
própria Melanie, temos que tomar seu trabalho desde o ponto de vista da estrutura de sujeito dedutível desta descrição. Aqui vemos uma criança na antítese da posição passiva frente à educação a que havia sido relegada pelas teorias de Anna Freud, para quem a contribuição da criança na etiologia dos seus sintomas não transcende da força de seus impulsos. Para Anna o "ponto de vista" da criança, o estritamente seu, seria meramente econômico, no sentido freudiano do termo. Acontribuição infantil seria acima de tudo libidinal. Melanie Klein, por sua vez, arrola a produção da criança, documenta seu processo, ressalta seu ponto de vista. Outros antes haviam dado voz à criança propriamente dita, mas foi acima de tudo Klein que acreditou nas suas associações.

\section{REFERENNCIAS BIBLIOGRÁFICAS}

ABRAHAM, Karl. (1973). Contribuiciones a la Teoria de la libido. La Primera Etapa Pregenital de la Libido. Buenos Aires. Ediciones Hormé. [1916].

FREUD, Anna. (1946). Psicoanalisis del niño. Buenos Aires. Ediciones Imán.

FREUD, S. ( 1990a.). Projeto de uma Psicologia Científica. In: Obras psicológicas completas. Rio de Janeiro, Imago, v.1 [1985].

FREUD, S. (1990 b). Três ensaios sobre a teoria da sexualidade. In: Obras psicológicas completas. Rio de Janeiro, Imago, v. 7 [1905].

FREUD, S. (1990 c). Análise de uma fobia em um menino de cinco anos. In: Obras Completas. Rio de Janeiro, Imago, V. [1909].

FREUD, S. (1990 d). Além do Princípio do Prazer. In: Obras psicológicas completas. Rio de Janeiro, Imago, v. 18 [1920].

PETOT, Jean-Michel. (1987). Melanie Klein Primeiras descobertas e primeiro sistema 1919-1932. São Paulo. Editora Perspectiva.

KLEIN, M.(1975 a). El Desarollo de un niño. In: Obras completas. Buenos Aires, PaidosHormé, v. Contribuciones Al Psicoanalisis. [1921].

KLEIN, M. (1975 b). Analisis infantil. In: Obras Completas. Buenos Aires, Paidos - Hormé, v. Contribuciones Al Psicoanalisis. [1923].

KLEIN, M. (1975 c). Simposium sobre analisis infantil. In: Obras Completas. Buenos Aires, Paidos-Hormé, v. Contribuciones $\mathrm{Al}$ Psicoanalisis. [1927]. 